\title{
The Role Social Media Marketing Plays in Customers' Purchase Decisions in the Context of the Fashion Industry in Saudi Arabia
}

\author{
Khald S. Alatawy ${ }^{1}$ \\ ${ }^{1}$ University of Tabuk, Saudi Arabia \\ Correspondence: Khald S Alatawy, faculty of Business Administration, Marketing Department, University of \\ Tabuk, PO box 741, 71491 Tabuk, Saudi Arabia. E-mail: ksalatawi@ut.edu.sa \\ Received: October 25, 2021 \\ Accepted: November 14, 2021 \\ Online Published: December 15, 2021 \\ doi:10.5539/ijbm.v17n1p117 \\ URL: https://doi.org/10.5539/ijbm.v17n1p117
}

\begin{abstract}
Globalization and rapid advancements in communication technologies have changed the way people throughout the world communicate with one another. Social media has grown in popularity as a technology that allows companies and consumers to communicate without being physically present. As a result, businesses in a variety of industries have turned to social media marketing (SMM) to boost consumer interactions, brand value and recognition, word of mouth, and sales. However, some socioeconomic and cultural characteristics in a given location have an impact on the usage of SMM. The growth of social media technology has resulted in a surge in social media users in Saudi Arabia, providing the opportunity for fashion businesses to leverage SMM to make great strides in this region. As a result, the current research project seeks to investigate how SMM (SMM) might influence customer purchase decisions in the Saudi Arabian fashion sector. In this respect, a self-administered online survey with a sample size of 106 participants was performed in the Kingdom of Saudi Arabia. According to the study's findings, there has been an increase in the usage of social media, and clients now prefer to shop online. Fashion businesses have a lot of potential to employ SMM to boost their brand value, awareness, identity, and word of mouth.
\end{abstract}

Keywords: marketing strategy, purchasing decisions, fashion industry, SMM

\section{Introduction}

This research examines the history of SMM in the fashion business, the gaps in the empirical literature, and the usage of social media in the Saudi Arabian fashion sector. Globalization and rapid advancements in communication technologies have changed the way people throughout the world communicate with one another. Social media has grown in popularity as a technology that enables companies and their consumers to communicate without being physically present (Tuten, 2020). Corporates have increasingly recognized the value of social media, and as a result, have included social media platforms in their marketing plans, owing to advantages such as increased internet speed, simplicity of use, and a rising number of internet users, among others. The development of the internet and the number of people using social media has prompted marketers to partake in SMM (Zhou \& Wang, 2014; Larimo \& Leonidou, 2021). The use of social media networks, tools, and technology to develop, transmit, promote, and trade an organization's services in order to create value for its stakeholders is known as SMM (Tuten \& Solomon, 2017). Customers may easily keep in touch with brands, retailers, and organizations through SMM (Chau \& Xu, 2012), allowing them to provide regular feedback to businesses (Tuten, 2020). Fashion retail businesses have embraced social media for the purpose of promoting their brands around the world, as they have increasingly recognized that social media has the ability to keep them linked to their clients, as the use and advantages of social media in marketing have grown (Kim \& Ko, 2012; Koivisto \& Mattila, 2018). As a result, it's critical to comprehend how fashion retailers may employ social media to impact and engage their customers (Evans, Bratton, \& McKee, 2021). There has been a scarcity of study on how customers' actual purchase choices can be impacted by SMM, despite the fact that there is a large body of literature on the use of social media to influence consumer buying intentions in the fashion retail business (Jin, 2012; Jahn, Kunz \& Mayer, 2012). The current study aims to fill this research vacuum by examining the influence of SMM on customers' real purchase decisions in the Saudi Arabian fashion sector. The purpose of this study is to ascertain if the implementation of a SMM strategy has an influence on customers' purchase decisions in the Saudi Arabian fashion sector. The underlying objectives are as follows: 1) To look at the influence of 
SMM on customers' purchase decisions in the Saudi Arabian fashion sector. 2) To investigate the extent and scope of SMM in the Saudi Arabian fashion sector. 3) To assess the present state of SMM in Saudi Arabia's fashion sector. 4) To provide recommendations for the Saudi Arabian fashion sector to improve its brand reach and penetration through SSM.

\section{Literature Review}

\subsection{The Saudi Arabian Fashion Industry}

Saudi Arabia's fashion sector is quickly expanding, as evidenced by a sales increase of US\$394 million in 2020. The annual revenue growth rate is anticipated to reach 4.5 percent by 2024 , with a market volume rise of US\$469 million by 2024. Apparel is now the largest category in Saudi Arabia's fashion retail business, with a market volume of US\$261 million (Statista, 2020). Furthermore, according to Al Nefaie, Khan, and Muthaly's (2019) research, Saudi Arabia's fashion sector is expanding at a quicker rate, and the number of social media users has grown substantially. According to reports, the number of social media users in Saudi Arabia's fashion sector increased to $50 \%$ in 2017 and is anticipated to rise to $70 \%$ by 2021 . Despite the growing popularity and use of social media in the fashion sector, revenue growth from SMM fell from $23 \%$ in 2016 to about $20 \%$ in 2017, with video advertising accounting for the majority of the decrease. In addition, revenue growth from SSM in the Saudi Arabian fashion sector is anticipated to drop by $9 \%$ in 2021. This drop may be linked to the fact that Saudi Arabia's Small and Medium Enterprises (SMEs) do not have market expertise and international exposure, making it difficult for them to build successful SMM strategies in the fashion sector (Hnell \& Ghauri, 2016; Gazzola, 2020). It is, therefore, critical for companies in the Saudi Arabian fashion retail sector to establish what factors must be addressed when building SMM strategies in order to influence consumers' purchasing decisions in the Saudi Arabian fashion industry. The purpose of this study was to evaluate the influence of SMM on client purchasing decisions in the Saudi Arabian fashion sector. With the passage of time, a significant portion of the business community has concentrated their efforts on developing a competitive brand using technological means in order to present a resourceful picture of their company in their respective sectors (Hsiao \& Chen, 2016). Brand management and branding through the use of technology are essential components of a business's success if aligned with market trends (Kotler \& Pfoertsch, 2007). In the fashion business, a brand is made up of intangible traits, symbols, and codes that transmit a compelling image of the product's quality and key aspects (Jin \& Cedrola, 2017). The use of digital technologies, such as online platforms and online media, to communicate and promote fashion companies to their clients has been shown to be beneficial in attracting customers in the fashion sector (Kalbaska \& Cantoni, 2018). Because cultural influences play such a large role in maintaining a company's brand identity, particularly in the fashion sector, the distinctive values and norms of conventions characterizing a community's lifestyle may affect how a company trades fashion items (Gazzola, 2020). Saudi Arabia's market is showing signs of pushback in the future. The notion of digital marketing and the growth of social media are discussed in this literature study. The importance of SMM in business sectors, as well as its tactics, is then examined and discussed in the context of Saudi Arabia. The paper concludes by reviewing the initial research question.

\subsection{Digital Marketing}

Various studies have been carried out in order to comprehend the growing relevance of digital marketing and its developing patterns in response to customer preferences (Muniesa \& Giménez, 2020). Digital marketing is a company's main marketing strategy. It involves leveraging digital/information and communication technology to advertise products or services via mobile phones, apps, display advertising, or other digital platforms (Deepak, 2018). In this regard, a survey conducted by Jena (2017) found that a substantial portion of the customer population prefers online buying to traditional shopping methods. Das (2016) also pointed out that the framework of SMM campaigns is impacted by gender, age, and a region's cultural values. Furthermore, according to Goel (2016), marketing firms view the use of digital marketing in terms of target market, technology implementation, content usage, social media integration, employee skills, and the budget they must impose on the advertisement media of the company marketing cost, and companies have found the use of digital media to be a very cost-effective method in this regard.

\subsection{The Development of SMM}

The term "social media" refers to the creation of online material that is freely accessible to the general audience. Borgan (2010) described social media as a change in people's attention to online social networking sites in a manner that encourages users to explore, share, and obtain information. Social media first emerged in 1986 (Storey et al., 2014). It all started with search marketing and a general commercial movement toward companies establishing an online presence, as inspired by global IT innovation. In light of highly upgraded 
accomplishments, this marketing technique has shown to be a sense of stimulating the corporate sector. SMM techniques aided in the promotion of business promotional tactics and resulted in a significant shift in the business domain. This success can be found in various areas, including the fashion industry, healthcare, construction, groceries, and other utility providers, all of which have seen impressive development due to the deployment of digital and SMM tactics (Zhang \& Wang, 2019). Social media platforms, like Twitter, Facebook, and Instagram, have become increasingly popular among people from all walks of life during the previous 10 years.

\subsection{Business Organizations' SMM Strategies}

Brands across all industries are increasingly interested in using SMM to build their businesses (Kim \& Ko, 2012). The potential worth of SMM-related business goods has been shown to be very effective in determining a company's performance (Muniesa \& Giménez, 2020). Several studies have shown that SMM is the most cost-effective and straightforward way to promote a brand with positive results. Internet technologies are the most successful scientific development that have benefitted a wide range of commercial fields (Kumar, 2011). Building an online system to give individuals an easy way to buy the products they need is a great concept. The user's convenience must be taken into consideration while choosing a suitable social media platform for marketing efforts. The most popular platforms include Twitter, Facebook, YouTube, Instagram, and Snapchat. The creation and implementation of SMM strategies ensure that a huge number of customers will be able to quickly and easily make purchases via SMM platforms.

\subsection{SMM for Fashion Industry}

In the fashion industry, digital technologies, particularly SMM techniques, are critical because they aid in the distribution of information, the promotion of brand recognition, and the development of appropriate techniques for education and learning about the textile and apparel businesses (Kalbaska \& Cantoni, 2018; Muniesa \& Giménez, 2020). Because the relationship between textile legacy and the adoption and adaptation of fashion trends and products is so important, fashion heritage incorporates both physical and intangible aspects such as cultural practises, social knowledge, and local knowledge (Permatasari \& Cantoni, 2019). The use of social media plays an important role in defining a brand's worth and identifying it among a large number of audiences in a cost-effective manner. Particular methods and techniques, according to Lipiäinen and Karjaluoto (2015), are beneficial in framing a brand's eminent identity through social media integration. In the context of luxury fashion businesses, Kim and Ko (2012) proposed five SMM constructs: entertainment, engagement, fashion consciousness, customization, and word of mouth. These allow luxury businesses to predict client purchase behaviour, albeit it should be noted that the degree of precision isn't always obvious.

\subsection{Customers' Purchasing Decisions as a Result of SMM}

According to previous research, people find it simple to utilize social media to buy items and obtain knowledge about different businesses. Furthermore, companies may use social media to get customers to pay a higher price using an effective marketing strategy (Godey et al., 2016). Godey et al. (2016) investigated the link between brand equity, consumer purchase intent, and fashion product price estimates. This approach may be used to design strategies for businesses. Laksamana (2018) performed another study that looked at the link between brand loyalty, purchase intent, and social media integration. According to H1, there is a favourable link between buyer intent and SMM strategies, and the results reveal a strong relationship between purchase intention and social media use. The relevance of this is explained by the fact that consumers find open discussion forums on social media platforms to be a simple way to assess information about brand credibility (Goel, 2016). The link between social media and brand loyalty in $\mathrm{H} 2$ revealed that these two factors had a strong relationship. People find it simple to judge the quality of fashion items on social media platforms because they are free to share their experiences, both positive and bad (Burmann, 2010). As a result, it can be deduced that companies with positive feedback and superior customer service tend to generate brand loyalty among customers, and brand trust is established in a shorter time than traditional methods of brand loyalty development. The findings revealed that the brand value and customers' purchase intentions are significantly linked through the use of social media.

\subsection{Saudi Arabian Fashion Industry and Customers Purchasing Intention}

Saudi Arabia is ranked $21^{\text {st }}$ out of all the world's reputable brands (Statista, 2019). According to Khan's (2019) research, the usage of social media in the purchase of luxury items is growing more common as buyers shift to digital modes of purchase. Research by Kamal et al. (2013) looked at the link between materialism and the desire to buy luxury fashion items among American and Arab social media users. This study, however, did not look at the impact of SMM on their purchasing intentions. In the Saudi Arabian fashion business, Maryam et al. (2015) investigated the elements that impact customers' involvement in social media for co-creation. This added to the 
growing body of evidence to demonstrate that social influence has a favourable impact on the desire to use social media for co-creation with firms. In comparison to traditional marketing approaches, Al Saud and Khan (2013) discovered that social media platforms, such as Facebook and Twitter, are beneficial for establishing a brand. However, there is a lack of data in many sectors, and further empirical studies could fill this gap in the existing literature. According to the current review, there are very few studies on the impact of SMM strategies in the Middle East/Saudi Arabia context, and their impact on customers' purchasing decisions has not been investigated, indicating a gap in the literature, particularly in Saudi Arabia's rapidly expanding fashion industry. As such, there are opportunities to enlighten future research in this area. The study found that SMM techniques had an influence on customers' decision-making processes. Through internet searching, consumers may now better comprehend and describe the qualitative characteristics of a product. With the advancement of digital marketing, this challenge of establishing brand identity has become much easier to address. People may now quickly gain exposure to a brand without having to spend a lot of time or money travelling. Customers may now purchase items online more easily and conveniently, thanks to the use of social media in digital marketing. People from various communities can easily communicate with one another via social media and will subsequently find it easier to estimate a brand's quality standards based on public comments on social media channels or discussions with people who have already purchased and experienced the product's quality. According to the study, businesses are increasingly relying on SMM to acquire customers in a competitive industry. As a result of the vacuum in the literature in the context of the Saudi Arabian fashion business, this research study intended to determine the extent to which an SMM strategy has an influence on customers' purchase decisions in the Saudi Arabian fashion market.

\section{Research Methodology}

A research study's temporal horizon might be cross-sectional or longitudinal, according to the study onion model given by Saunders et al. (2019). A cross-sectional time horizon was chosen for this research study because it allowed the researcher to investigate phenomena at a specific moment in time, and cross-sectional time horizons are commonly used in academic research. The most appropriate data collecting instrument when a quantitative research technique is combined with a survey as a research plan is a questionnaire survey. A questionnaire generally consists of a variety of questions that serve as a foundation for the researcher's interpretation (Saunders et al., 2019). The questionnaire for this research study was divided into two portions, the first of which dealt with the respondents' demographic information, and the second of which inquired about their purchasing decisions as influenced by the usage of social media. Due to time and financial restrictions and the worldwide pandemic (COVID-19), an online survey was the instrument of choice, and Google Forms was utilized to conduct the questionnaire survey. The ability to export replies to a spreadsheet for data analysis makes Google Forms a great tool for online questionnaire surveys. In addition, utilizing Google Forms makes it easier to create questionnaires with different scales and formats for simplicity of use (Schindler, 2018). The Google Form link was shared with the responders via email and social media sites such as Facebook, Twitter, and Instagram, using personal and professional references. After the replies were obtained, the incomplete responses were removed, resulting in a total of 106 responses. Because the participants in this study were people who use social media and shop for clothes online, the population of this study consisted of people who use social media and shop for clothes online. However, because access to all social media users is not practical, the researcher chose a sample that represented the social media users of a specific demographic. A sample is a part of a population that includes all of the features of that population (Saunders et al., 2019). A simple random sample approach was chosen as the appropriate sampling strategy for this research project. Using this sample approach, links to Google Form surveys were delivered to social media users in Saudi Arabia via emails and social networking sites.

\section{Data Analysis}

\subsection{Use of Social Media}

The respondents were asked if they utilize social media sites. 93.4 percent of those polled claimed to use social media networks. Those who did not utilize social media sites (6.6 percent) were requested not to participate any further in the research.

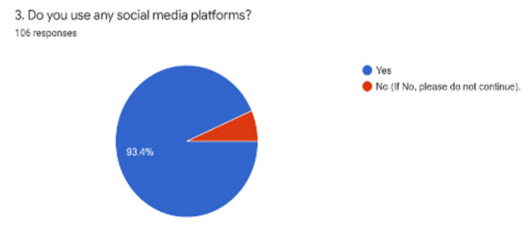




\section{Figure 1. Social Media Platforms}

Following the question of whether respondents use social media, the participants were asked which platform they liked to use the most out of Facebook, Twitter, YouTube, Instagram, Snapchat, WhatsApp, Pinterest, and other options. According to the results of the data analysis, the bulk of the respondents use Snapchat (71.7\%), Instagram (57.5\%), Twitter (56.6\%), YouTube (44.3\%), Facebook (15.1\%), and WhatsApp (2.8\%), and the remainder use Pinterest, Reddit, and Telegram. According to the statistics, Snapchat, Twitter, YouTube, Instagram, and Facebook are the most popular social media sites in Saudi Arabia.

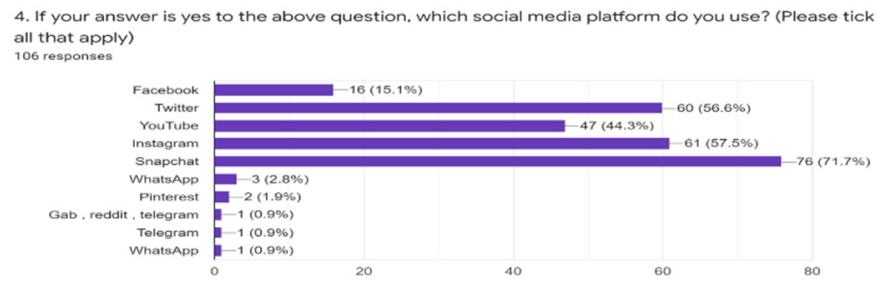

Figure 2. Use of a particular social media platform

\subsection{Online Buying as a Result of SMM}

Respondents were asked if they had ever purchased a product as a consequence of a business's use of SMM. According to the findings of the data study, 73.6 percent of respondents have purchased items as a consequence of a business's social media promotion, whereas 13.2 percent of respondents stated that they had never purchased anything after being inspired by a business's SMM. Customers looking to purchase fashion goods are more likely to be affected by SMM, as emphasized by the predominance of answers that referred to making real purchases after being inspired by SMM.

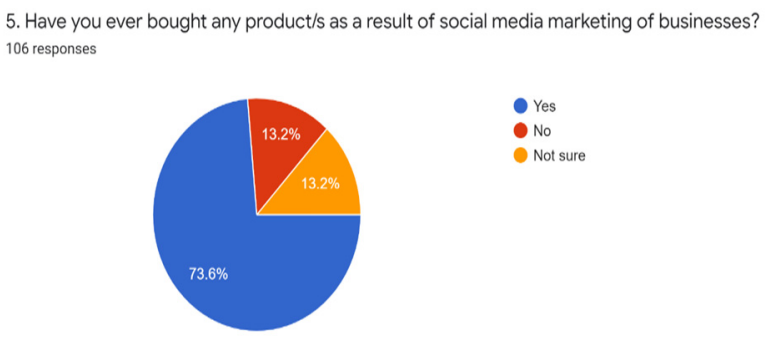

Figure 3. Purchasing a product as a result of SMM

The participants were asked if they had ever purchased a product as a consequence of a business's social media promotion. According to the findings of the data study, 73.6 percent of respondents had purchased items as a consequence of a business's use of SMM. In contrast, $13.2 \%$ of respondents stated that they have never purchased anything as a result of being inspired by a business's SMM. Customers who are interested in purchasing fashion goods are more likely to be affected by SMM, as seen by the majority of answers to making real purchases after being inspired by SMM.

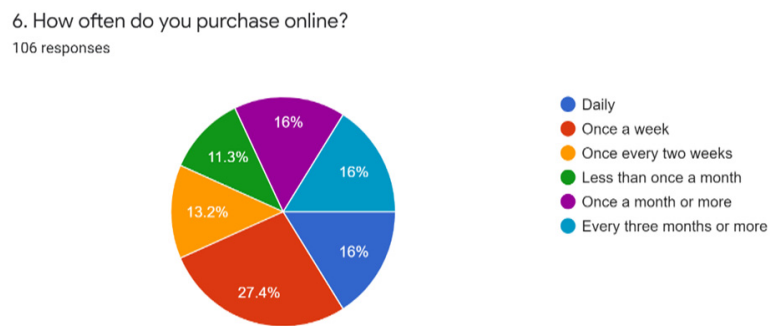


Figure 4. Frequency of Online Purchase

\subsection{Advertisements on Social Media Platforms}

Respondents were asked if they regularly see fashion brand advertising on social media sites. According to the findings of the data study, 54.7 percent of the 106 respondents believed they had seen fashion brand ads on social media sites. While 20.8 percent said they had never seen any advertising on social media, 17.9 percent said they weren't sure if they had seen fashion brand advertisements on social media sites.

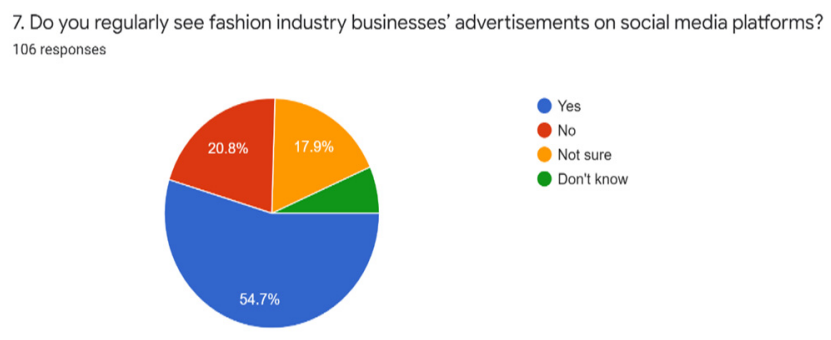

Figure 5. Advertisements on Social Media Platform

Respondents were also asked how many times they saw advertising on social media, which was an extension of the previous topic. According to the findings, 29.2 percent of respondents saw advertisements 1-5 times per week, 24.5 percent saw adverts 1-5 times per month, 13.2 percent saw advertisements more than 5 times per week, 12.3 percent believed they saw advertisements more than 5 times per month, and 11.3 percent saw adverts 1-5 times per year, with only 9.4 percent revealing they had seen fashion brand advertisements more than 5 times per year.

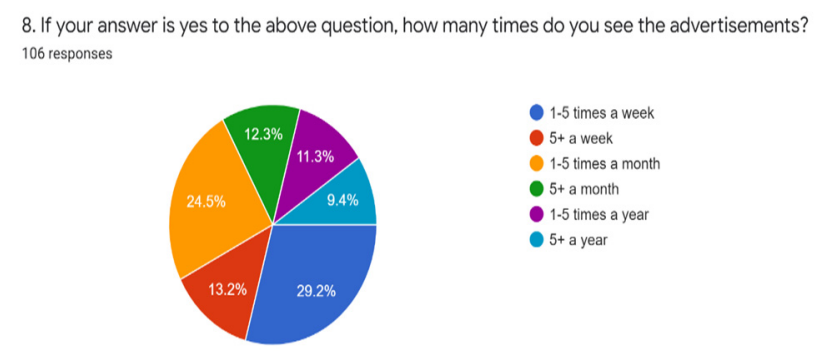

Figure 6. Frequency of watching advertisements

Respondents were also questioned if they pay attention to how firms in the fashion sector use SMM. According to the findings of the data study, 41.5 percent paid attention to fashion companies' SMM, while 34.9 percent paid attention sometimes. On the other side, $17.9 \%$ of respondents said they didn't pay attention to fashion businesses' SMM.

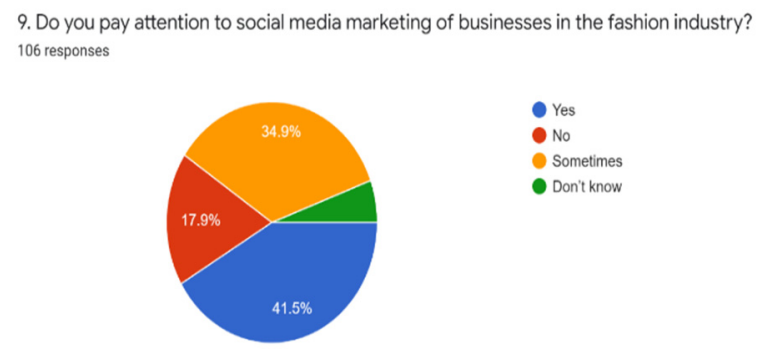

Figure 7. Attention towards the SMM

\subsection{Impact of SMM on Purchasing Decision}

The survey's respondents were asked about the influence of SMM on their purchase decisions. According to the findings of the data analysis, 39.6\% of respondents said that SMM had a minor influence on their purchase 
choices. 32.1 percent said SMM had a big influence on their buying choice, while 17 percent said it had a little impact. 11.3 percent said SMM had no influence on their buying choice.

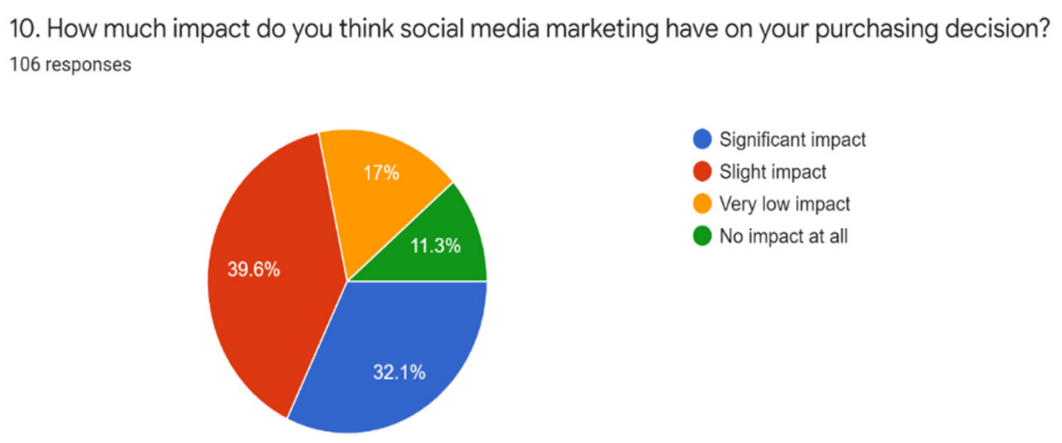

Figure 8. Impact of SMM on Purchasing Decision

\subsection{Attitude towards SMM}

The influence of SMM on respondents' purchase decisions was inquired about in the study. According to the findings of the data analysis, $39.6 \%$ of respondents said that SMM had a minor influence on their buying choice. SMM had a major influence on 32.1 percent of respondents' purchase decisions, while 17 percent said it had a very low impact. 11.3 percent said SMM had no influence on their purchase choices.

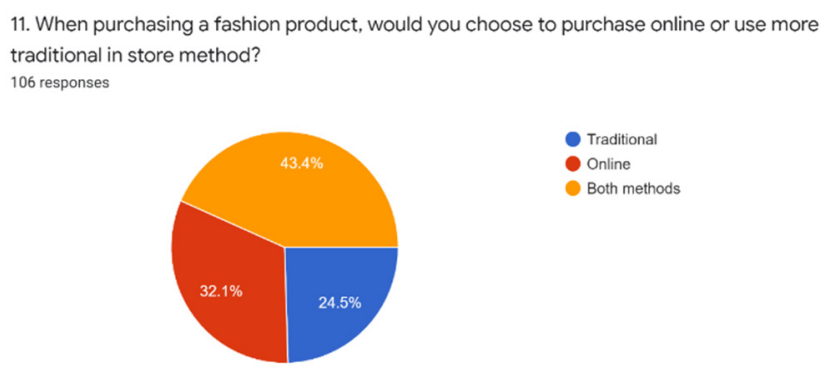

Figure 9. Preferred Mode of Shopping

Respondents were also questioned if they found it simple to buy items using social media sites. 57.5 percent of respondents said they found it simple to buy fashion items on social media. 19.8 percent of respondents said they were unaware, while 14.2 percent said they were unsure.

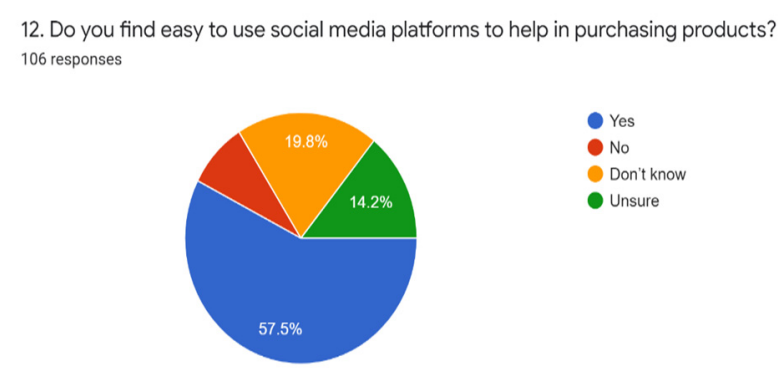

Figure 10. Ease of using social media platforms

Respondents were also questioned whether SMM is more effective than traditional marketing in attracting clients. According to the findings of the data analysis, 47.2 percent of respondents believed that SMM is more successful than traditional marketing in attracting customers. While 22.6 percent strongly agreed, 15.1 percent disagreed, 
and 13.2 percent said they didn’t know.

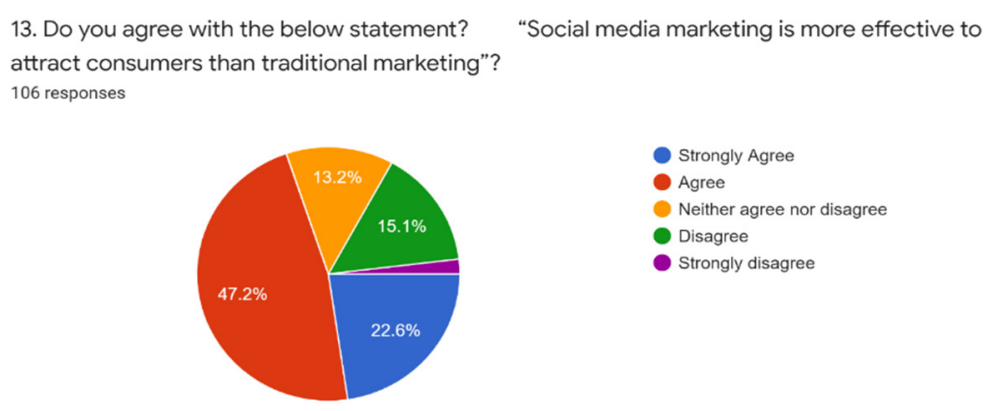

Figure 11. Effectiveness of SMM

The respondents were asked if they felt that SMM had enhanced their purchasing experience. Data analysis indicated that 51.9 percent of 106 respondents agreed, and 23.6 percent disagreed. $19.8 \%$, on the other hand, had no idea.

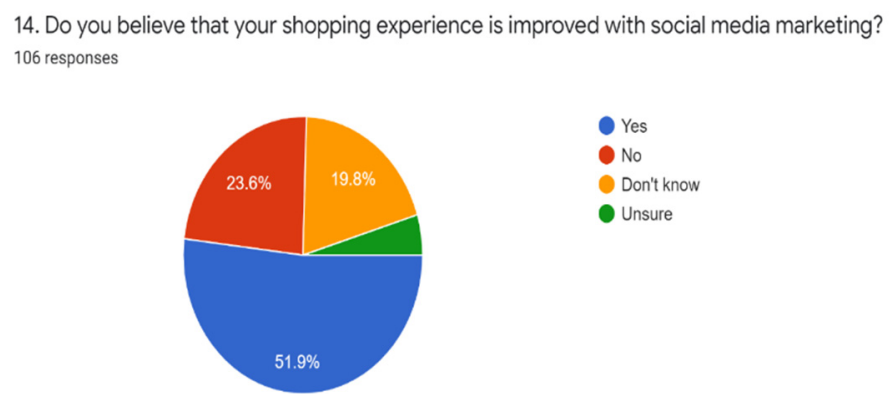

Figure 12. Improvement in shopping experience

\subsection{Future Growth of SMM in Saudi Arabia}

Furthermore, the respondents were questioned if SMM for fashion sector firms is a viable option in Saudi Arabia. In response, 66 percent said yes, 13.2 percent said they didn't know, 12.3 percent said they disagreed, and 8.5 percent said they weren't sure.

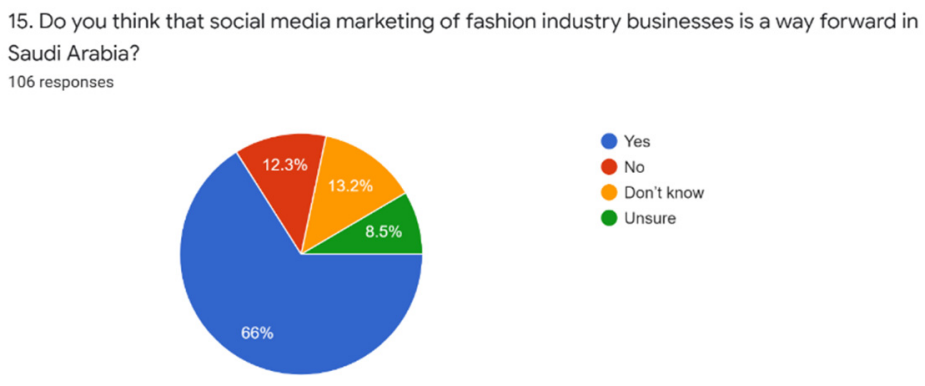

Figure 13. Way Forward for SMM in Saudi Arabia

The next question sought the respondent's opinion on the competitive advantage of fashion firms based on social media and information technology. Respondents were asked how they felt about Saudi Arabian business market trends in terms of the potential expansion of IT and social media to achieve a competitive edge. $38.7 \%$ agreed, $28.3 \%$ strongly agreed, and 25.5 percent said they didn't agree or disagree. The number of those who disagreed was insignificant. 


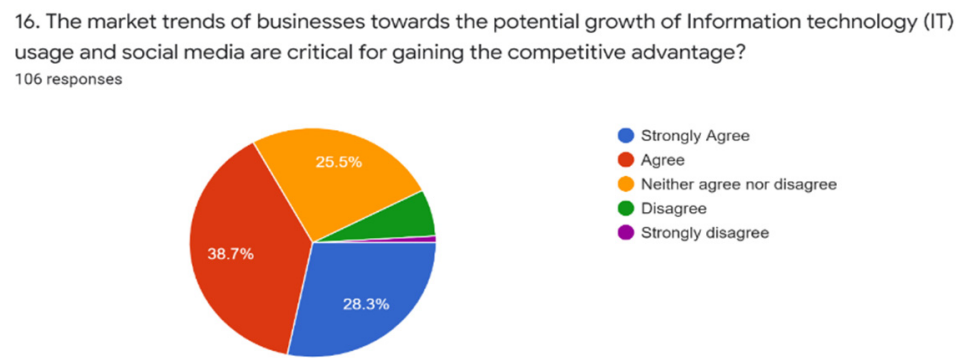

Figure 14. Potential Growth of IT Usage and Social Media

The participants were also asked: 'Where do you think SMM may benefit firms in the fashion industry?' According to the findings of the data analysis, SMM can aid in the development of brand value (49.1\%), market recognition (39.6\%), customer engagement (34.9\%), active presence $(32.1 \%)$, customer base $(25.5 \%)$, setting trends $(23.6 \%)$, framing identity (23.6\%), and word of mouth (23.6\%) (13.2 percent).

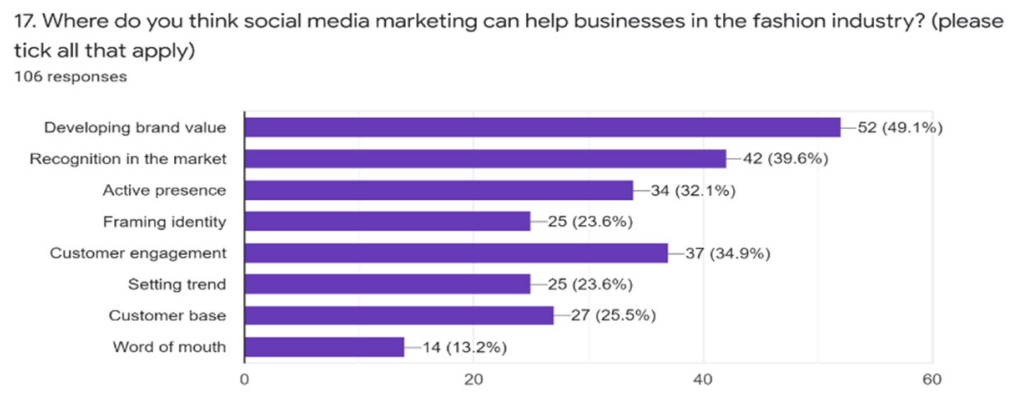

Figure 15. Benefits of SMM in the Fashion Industry

\section{Discussion}

The goal of the current study was to see how SMM influenced customer purchase decisions in the Saudi Arabian fashion sector. The findings indicated that a variety of factors, such as socio-cultural variables, influence customers' attitudes about SMM. Customers are fully aware of SMM, according to the research, due to the increased usage of the internet, which has made them more informed and knowledgeable than before. The bulk of the respondents were between the ages of 25 and 38, indicating a rising trend of social media use in Saudi Arabia. According to Das, demographic charterers have a significant role in determining the structure of digital marketing in a certain location (2016). He stated that the gender, age groupings, and cultural values of a specific location impact the structure of digital media marketing. As a consequence of the demographic findings, both male and female users of social media are equally active, which might influence fashion businesses' SMM in Saudi Arabia. This is further evidenced by customers' usage of other social media platforms, including Snapchat, Instagram, Facebook, and YouTube, all of which highlight an intriguing aspect: individuals utilize various social media tools whether or not they plan to buy something. Also, with the usage of social media platforms, there has been a rising tendency among customers to buy items online. The majority of respondents also stated that they shop online once a week (27.4\%), supporting Kamal et al., (2013) findings that the purchase intention for luxury fashion products in Arab and American social media users is on the rise due to a significant link with materialism. The conclusions of this study agree with those of Zhang and Wang (2019), who believe that SMM techniques have aided in the promotion of company promotional tactics and have resulted in a significant shift in the business sector. Fashion businesses in Saudi Arabia are contemplating ads on social media platforms as a SMM approach, according to key study results on advertisement use on social media platforms. Furthermore, the majority of respondents $(29.2 \%)$ said they saw fashion brand advertisements on social media sites 1 to 5 times each week. These commercials are well-received by a large majority of respondents ( 41.5 percent). In terms of the impact of SMM on purchasing decisions, the findings revealed a positive relationship between the two variables, with 32.1 percent reporting that it has a significant impact on their decision to buy online, confirming Laksamana's (2018) findings that social media not only influences buying decisions but also shapes brand 
loyalty to a greater extent. Furthermore, customers are increasingly turning to online channels for purchasing fashion brands, which are easier to use, particularly on social media platforms. Consumer purchasing experiences have been enhanced as a result of online purchases, as evidenced by Goel's research findings (2016). The data also show that owing to rising innovation in communication technology, the potential of SMM for fashion businesses in Saudi Arabia is vast. The findings also suggest that using SMM to increase brand recognition, brand value, customer engagement, active presence, customer base, setting trends, framing identity, and word of mouth could be a source of sustainable competitive advantage, which supports Maryam et al. (2015) as well as Lipiäinen and Karjaluoto's research findings (2015). As a result of the above discussion, it can be concluded that fashion company brands in Saudi Arabia realize the benefits connected with the usage of SMM, which has been found to be favourably related to consumer purchasing choices.

\subsection{Study Contributions}

The study makes an important contribution to the implementation of a SMM strategy which has an influence on customers' purchase decisions in the Saudi Arabian fashion sector. The study has identified the influence of SMM on customers' purchase decisions and the extent and scope of SMM in the Saudi Arabian fashion sector. The study assessed the present state of SMM in Saudi Arabia's fashion sector. The study found that fashion businesses have a lot of potential to employ SMM to boost their brand value, awareness, identity, and word of mouth.

\section{Conclusion}

The primary goal of the core research project was to look at how SMM influences customer purchase decisions in the Saudi Arabian fashion sector. In this case, a quantitative research technique based on positivist philosophy was adopted, with an online survey serving as the study strategy. The online questionnaire study was performed in Saudi Arabia and was aimed at fashion-inspired social media users. According to the findings of the research study, there has been a growing tendency among Saudi Arabian customers to not only purchase online but also to seek product-related information via social media platforms. They also spend more time on social media and pay greater attention to the marketing of Saudi Arabian fashion businesses. This shows that the chance of social media users purchasing fashion goods online is increasing, which has major implications for Saudi Arabia's fashion sector. The number of people using social media in Saudi Arabia is expected to rise as information technology advances. Furthermore, previous research has revealed a tendency of purchasing premium fashion products among Saudi Arabian customers, implying that fashion businesses have more opportunities in SMM. Fashion brands will certainly benefit from SMM in terms of brand recognition, brand value, consumer interaction, and brand identity framing in order to get a competitive edge in the market. As a result, companies may leverage the social media market to offer convenience while also improving the purchasing experience of Saudi Arabian consumers. In a nutshell, it can be said that the usage of SMM has a considerable impact on customer purchase decisions in the Saudi Arabian fashion sector. Furthermore, to enhance consumer engagement and base, the following recommendations may be given for firms in the fashion industry: 1) To increase traffic to their social media accounts and improve sales, fashion businesses can utilize more effective technologies such as mobile applications, search engine optimization strategies, and so on. 2) Fashion businesses could utilize internet influencers as brand endorsers to influence Saudi Arabian customers' purchase decisions. At the same time, celebrity endorsement might be a successful technique for influencing customer purchase behaviour on social media. 3) Fashion businesses must also incorporate innovative features into their SMM. This might also help a company improve its online customer service, which is an essential factor for customers to consider when buying a product. The current research study can be repeated in the future with the same theoretical foundation, but the relationship between the dependent and independent variables can be tested further with the mediating or moderating effect of cultural variables, word of mouth, or demographic factors such as gender or occupation. Furthermore, a bigger sample size might be employed in future studies. A case study technique may be used to undertake the same research study focused on a specific fashion brand firm in Saudi Arabia. Furthermore, in addition to an online survey, an experiment may be utilized as a data collecting tool to aid researchers in determining the potential of SMM in the Saudi Arabian fashion sector.

\section{References}

Al Saud, A.A. and Khan, M.R., 2013. Role of social media in brand development in Saudi Arabia. European Journal of Business and Economics, 8(1). https://doi.org/10.12955/ejbe.v8i1.1

ALNefaie, M., Khan, S., \& Muthaly, S. (2019). Consumers' electronic word of mouth-seeking intentions on social media sites concerning Saudi bloggers' YouTube fashion channels: an eclectic approach. International Journal of Business Forecasting and Marketing Intelligence, 5(1), 1-22. 
https://doi.org/10.1504/ijbfmi.2019.10020486

Barile, S., \& Saviano, M. (2014). Handbook of Research on Management of Cultural Products. Retrieved from https://www.igi-global.com/chapter/resource-integration-and-value-co-creation-in-cultural-heritage-manage ment/104859

Behari, D. B. (2016). Engagement Pattern of Users in Digital and Social Media Marketing DSMM A Service Industry Perspective. KIIT University.

Bell, E., Bryman, A., \& Harley, B. (2018). Business research methods. Oxford university press.

Beskow, L. M., Check, D. K., \& Ammarell, N., (2014). Research participants' understanding of and reactions to certificates of confidentiality. $A J O B$ Empirical Bioethics, 5(1), 12-22. https://doi.org/10.1080/21507716.2013.813596

Brogan, C., (2010). Social media 101: Tactics and tips to develop your business online. John Wiley \& Sons.

Burmann, C. (2010). A Call for User-Generated Branding. Journal of Brand Management, 18(1), 1-4. https://doi.org/10.1057/bm.2010.30

Campbell, S. R., Anitsal, I., \& Anitsal, M. M. (2013). Social media's key success factors: An analysis of customer reactions. Business Studies Journal, 5(1), 43-57.

Carim, L., \& Warwick, C. (2013). Use of social media for corporate communications by research-funding organisations in the UK. Public Relations Review, 39(5), 521-525. https://doi.org/10.1016/j.pubrev.2013.08.006

Creswell, J. W. (2014). A concise introduction to mixed methods research. SAGE publications. https://doi.org/10.4135/9781473991712

Creswell, J. W., \& Creswell, J. D. (2017). Research design: Qualitative, quantitative, and mixed methods approaches. Sage publications.

Dauriz, L., Remy, N., \& Sandri, N. (2014). Luxury shopping in the digital age. In M. Toriello (Ed.), Perspectives on retail and consumers goods (pp. 26-31). USA: McKinsey \& Company. Retrieved from

Deepak, V. (2018). A Critical Review of Digital Marketing.

Evans, D., Bratton, S., \& McKee, J. (2021). Social media marketing. AG Printing \& Publishing.

Fashion United. (2019) Global Fashion Industry Statistics. Retrieved from https://fashionunited.com/global-fashion-industry-statistics/

Gazzola, P., Pavione, E., Pezzetti, R., \& Grechi, D. (2020). Trends in the fashion industry. The perception of sustainability and circular economy: A gender/generation quantitative approach. Sustainability, 12(7), 2809. https://doi.org/10.3390/su12072809

Ghauri, P., Grønhaug, K., \& Strange, R. (2020). Research methods in business studies. Cambridge University Press. https://doi.org/10.1017/9781108762427.004

Godey, B., Manthiou, A., Pederzoli, D., Rokka, J., Aiello, G., Donvito, R., \& Singh, R. (2016). Social media marketing efforts of luxury brands: Influence on brand equity and consumer behavior. Journal of business research, 69(12), 5833-5841. https://doi.org/10.1016/j.jbusres.2016.04.181

Goel, D. (2016). What factors affect Digital Marketing? Retrieved from https://www.linkedin.com/pulse/what-factors-affects-digital-marketing-deepak-goel_

Hanaysha, J. R. (2018). An examination of the factors affecting consumer's purchase decision in the Malaysian retail market. PSU Research Review, 2(1), 7-23. https://doi.org/10.1108/prr-08-2017-0034

Hånell, S. M., \& Ghauri, P. N. (2016). Internationalization of smaller firms: Opportunity development through networks. Thunderbird International Business Review, 58(5), 465-477. https://doi.org/10.1002/tie.21763

Hsiao, K. and Chen, C. (2016) What drives in-app purchase intention for mobile games? An examination of perceived values and loyalty. Electronic Commerce Research and Applications, 16, 18-29.

Jahn, B., Kunz, W., \& Meyer, A. (2012). The role of social media for luxury brands-Motives for consumer engagement and opportunities for business. In Identitätsbasierte Luxusmarkenführung (pp. 221-236). Springer Gabler, Wiesbaden. https://doi.org/10.1007/978-3-8349-4060-5_14

Jin, B., \& Cedorala, E. (2017). Brands as Core Assets: Trends and Challenges of Branding in Fashion Business. Fashion Branding and Communication, 1-39. https://doi.org/10.1057/978-1-137-52343-3_1 
Jin, S. A. A. (2012). The potential of social media for luxury brand management. Marketing Intelligence \& Planning. https://doi.org/10.1108/02634501211273805

Kalbaska, N., \& Cantoni, L. (2018) Digital Fashion Competencies: Market Practices and Needs. Business Models and ICT Technologies for the Fashion Supply Chain, 125-135. https://doi.org/10.1007/978-3-319-98038-6_10

Kamal, S., Chu, S. C., \& Pedram, M. (2013). Materialism, attitudes, and social media usage and their impact on purchase intention of luxury fashion goods among American and Arab young generations. Journal of Interactive Advertising, 13(1), 27-40. https://doi.org/10.1080/15252019.2013.768052

Khan, M. (2019) The Impact of Perceived Social Media Marketing Activities: An Empirical Study in Saudi Context. International Journal of Marketing Studies, 11(1), 134. https://doi.org/10.5539/ijms.v11n1p134

Kim, A. J., \& Ko, E. (2012). Do social media marketing activities enhance customer equity? An empirical study of luxury fashion brand. Journal of Business Research, 65(10), 1480-1486. https://doi.org/10.1016/j.jbusres.2011.10.014

Koivisto, E., \& Mattila, P. (2018). Extending the luxury experience to social media - Usergenerated content co-creation in a branded event. Journal of Business Research. https://doi.org/10.1016/j.jbusres.2018.10.030

Kotler, P., \& Pfoertsch, W. (2007). Being known or being one of many: The need for brand management for business-to-business (B2B) companies. Journal of Business \& Industrial Marketing, 22(6), 357-362. https://doi.org/10.1007/3-540-44729-6_1

Kumar, P. (2012). Information and Communication Technology in Textile Engineering College Libraries of Haryana, India. Information and Knowledge Management, 1(3), 7-16.

Laksamana, P. (2018) Impact of Social Media Marketing on Purchase Intention and Brand Loyalty: Evidence from Indonesia's Banking Industry International Review of Management and Marketing, 8(1), 13-18. https://doi.org/10.15405/epsbs.2017.12.02.4

Li, F., Larimo, J., \& Leonidou, L. C. (2021). Social media marketing strategy: definition, conceptualization, taxonomy, validation, and future agenda. Journal of the Academy of Marketing Science, 49(1), 51-70. https://doi.org/10.1007/s11747-020-00733-3

Lipianen, H., \& Karjaluoto, H. (2015) Industrial branding in the digital age. Journal of Business \& Industrial Marketing, 30(6), 733-741.

Mandal, A. (2019). Customer Preference in the Virtual Retail Environment-An Empirical Study about Online Shopping in India. Parikalpana: KIIT Journal of Management, 15(1/2), 239-240. https://doi.org/10.15520/jassh210131

Maryam, A., Maarop, N., \& Ibrahim, R. (2015). Factors influencing customers' engagement in social media for co-creation in the fashion industry of Saudi Arabia. International Conference on Information Technology \& Society, 53-63.

Moctezuma, N. P. B., \& Rajagopal. (2016). Role of digital marketing in driving business performance in emerging markets: an analytical framework. International Journal of Business Forecasting and Marketing Intelligence, 2(4), 291-314. https://doi.org/10.1504/ijbfmi.2016.080127

Muniesa, R. L., \& Giménez, C. G. (2020). The Importance of the Loyalty of Fashion Brands through Digital Marketing. Journal of Spatial and Organizational Dynamics, 8(3), 230-243.

Permatasari, P., \& Cantoni, L. (2019) Mapping Mobile Apps on Batik: A Journey Across Heritage and Fashion. Fashion Communication in the Digital Age, 166-178. https://doi.org/10.1007/978-3-030-15436-3_15

Rubin, A., \& Babbie, E. R. (2016). Empowerment series: Research methods for social work. Cengage Learning.

Saunders, M. N. K., Lewis, P., \& Thornhill, A. (2019). Research Methods for Business Students (8th ed.). Harlow.

Schindler, E. (2018). The Best Online Survey Tools of 2018.

Statista. (2020). Fashion - Saudi Arabia | Statista Market Forecast. Retrieved 1 May 2020, from https://www.statista.com/outlook/244/110/fashion/saudi-arabia

Storey, M. A., Singer, L., Cleary, B., Figueira Filho, F., \& Zagalsky, A. (2014). The evolution of social media in software engineering. In Proceedings of the on Future of Software Engineering (pp. 100-116). ACM. https://doi.org/10.1145/2593882.2593887 
Tuten, T. L. (2020). Social media marketing. Sage.

Zhang, P., \& Wang, C. (2013). The Evolution of Social Commerce: An Examination from the People, Business, Technology, and Information Perspective. Retrieved https://papers.ssrn.com/sol3/papers.cfm?abstract_id=2352587

Zhou, L., \& Wang, T. (2014). Social media: A new vehicle for city marketing in China. Cities, 37, $27-32$. https://doi.org/10.1016/j.cities.2013.11.006

\section{Copyrights}

Copyright for this article is retained by the author(s), with first publication rights granted to the journal.

This is an open-access article distributed under the terms and conditions of the Creative Commons Attribution license (http://creativecommons.org/licenses/by/4.0/). 